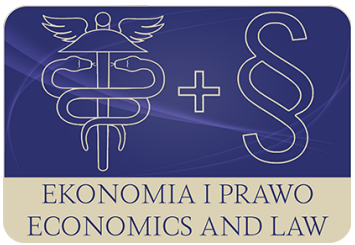

EKONOMIA I PRAWO. ECONOMICS AND LAW

Volume 15, Issue 4, December 2016

p-ISSN 1898-2255, e-ISSN 2392-1625

www.economicsandlaw.pl

ORIGINAL ARTICLE

received 18.10.2015; revised 06.07.2016; accepted 31.12.2016

Citation: Eyszczarz, B. (2016). The effect of health care model on health systems' responses to economic crises. Ekonomia i Prawo. Ecomomics and Law, 15(4): 493-501. doi:10.12775/EiP.2016.033.

\title{
The effect of health care model on health systems' responses to economic crises
}

\author{
BEAŻEJ ŁYSZCZARZ \\ Nicolaus Copernicus University, Faculty of Health Sciences, Department of Public Health, \\ ul. Sandomierska 16, 85-830 Bydgoszcz, Poland \\ $\square$ blazej@cm.umk.pl
}

\begin{abstract}
Motivation: The paper is concerned with relationships between model of health care and the responses of health systems to economic crises in OECD countries (1970-2013).

The institutional arrangements are considered to affect the operation and performance of health systems in several ways; however, so far the topic has not been investigated in the economic crises context.

Aim: This research attempts to bridge this gap by comparing the dynamics of health systems measures (male and female life expectancy; health expenditure; and doctors' density) during years of recession with the average annual growth rate of the same measures for the countries clustered in four model groups.

Results: The results show that the health care model applied is related with the systems' responses to economic downturns. The Bismarck-type countries perform poorly in terms of health improvement and are incapable of containing costs during recessions. The Beveridge-type countries perform better in health improvement during stagnation; they also have effective cost-containment policies but they provide less security in terms of human resources for health than the Bismarck-type states. The market-oriented countries are in a superior position in health improvement when economies collapse; however, they fail to restrict health expenditure increase and to sustain the dynamics of doctors' availability.

The systems in transitions are characterized by a relatively low performance in female health improvement during recessions, a moderate situation in securing access to physicians and the greatest possibilities of containing costs. For the policymakers, the results imply that there is no universally superior model of health care organization.
\end{abstract}

Keywords: health systems; economic crises; OECD; institutions; health status JEL: H51; I10; I18 


\section{Introduction}

The economic crisis which began in 2008 has significantly impacted public policies in welfare states. Health systems are potentially vulnerable to declining public financing during recessions, resulting in restricted access to health services and health deterioration of those that are harmed by unemployment and decreasing incomes. There is a rich body of public health literature that focuses on the impact of economic downturns on health; however, there is no clear evidence on the direction and strength of the relationships involved ${ }^{1}$.

Another relevant area of health policy research focuses on the impact of health care institutional arrangements on the operation of national health systems. Institutions play an important role in the performance of economic systems and health care is also subject to institutional analyses. One of the general approaches to evaluate the institutional aspects of health care uses a typology of health care models. The most common typology distinguishes the Bismarck (social health insurance) model; the Beveridge (National Health Service) model; and the market-oriented (private health insurance) model, however also other typologies and models are defined in the literature (Lee et al., 2008, p. 105-113; Docteur \& Oxley, 2003). Other aspects of health care institutional framework include a public-private mix in ownership and financing; reimbursement policies and organization of health services delivery.

This research attempts to link the two above areas of health care analysis. So far, the interest in the institutional characteristics of health care was not investigated in the economic crises context. Thus, the novelty of this paper is expressed in combining the two aspects. The hypothesis formulated in this paper is that the health care model applied differentiates the responses of health systems to economic downturns.

\section{Methodology}

This part explains concepts applied for the empirical analysis as well as provides details on the methods and data sources used.

\subsection{Concepts}

World Health Organization (WHO, 2000, p. 5) defines the health system as 'all the activities whose primary purpose is to promote, restore or maintain health'. This definition exemplifies a very broad approach to delimiting the boundaries of health system. Numerous authors narrow the concept of health system to solely those activities that not only are focused mainly on health but are concerned with producing health care services. Mills and Ranson (2012, p. 615), for example, state that the health system consists of those organizations, institutions, and resources that deliver health care to individuals. Clearly, health sys-

${ }^{1}$ For the recent review see: Suhrcke \& Stuckler (2012, p. 647-653). 
tems are very complex themselves and empirical analyses concerned with them are limited to selected aspects of their operation. Here, these aspects are health status, health expenditure and human resources availability. The above are often considered to be crucial characteristics of health system operation, still, there are many other aspects of health care that are inspected in the literature, e.g. health inequalities, quality of care, health care utilization, organization of care.

This paper aims to explain the effect of economic crises on the operation of health systems. Yet, there is no clear and indisputable definition of the economic crisis; here, this term is defined as negative gross domestic product (GDP) growth during a year. This way of defining a crisis is driven by the characteristics of the dataset; the annual data is used for time-series of both GDP and health system measures.

Institutional characteristics of health systems are defined as a system of economic regulations and interactions including ownership structure, organization of financial and material resources flows as well as rules that regulate access to goods and services exchanged in health markets (Eyszczarz, 2014, p. 66). Since the inclusion of all these institutional aspects of health care is extremely difficult in a single research, I only focus on one institutional aspect, namely, the health care model. The classification of health system according to the model implemented has a long tradition and has been applied in numerous influential researches in health policy.

There are four types of health care models distinguished here: Bismarck; Beveridge; market-oriented; and system in transition. The assignment to one of the model groups is generally based on the source of financing; however, this criterion is not strictly followed here. The Bismarck-type (social health insurance; SHI) systems are financed predominantly by means of earmarked premiums, mainly from salaried employees. The Beveridge (national health services; NHS) systems are funded primarily through general taxation. The market-based systems here are those in case of which private sources of financing constitute at least $40 \%$ of current health spending. The last model, the systems in transitions, is not identified by the source of financing; instead it groups the transition economies of Central Europe with health system still being in the process of transformation from centrally managed organization to market-oriented mechanisms. Applying a formal criterion of funding source, all these countries have the SHI model, however, as it is argued below they should rather be treated as a separate group.

\subsection{Methods and data}

This research uses a dynamic analysis of measures describing the operation of health systems in OECD countries in the period of 1970-2013. The measures used are: (1) female and (2) male life expectancy (LE) at birth, (3) current expenditure on health as a proportion of GDP (HE_GDP), and (4) number of physicians per 1000 population. The first two variables proxy the population health 
status, the third stands for the share of economy's resources devoted to health care activities, while the last measure approximates the availability of human resources for health.

The data used is taken from OECD's statistical databases: OECD Health Database and OECD Statistics, which are online data sources that contain information on various aspects of OECD members' economies and social issues.

\section{Research process}

To identify the impact of economic crises on health system $x$, the dynamics of a measure (LE, HE_GDP or doctors' density) in a year when GDP declined is compared with the average annual growth rate (AAGR) of this measure for the country $x$ during the whole period of analysis.

In the case of life expectancy and doctors' density lower than average dynamics of a measure in a year of recession suggests that an economic downturn affected health status and human resources availability negatively. On the other hand, a lower than average growth rate of health expenditure when GDP declined is considered to be positive as it indicates a greater ability of a country to adopt cost-containing policies.

After identifying single recession cases (declining GDP in country $x$ in year t) they are grouped according to the model the country belongs to. For each of the four health care model groups the share of recession country-years ${ }^{2}$ in which the dynamics of the measure was lower than on average is identified. This allows for distinguishing the models according to their responses to economic downturns.

\section{Results}

The results of the empirical analysis are reported in three stages. The first stage is concerned with the assignment of countries to four model groups. In the second step, I analyse the dynamics of measures describing health systems operation. The third part investigates whether the health care model implemented differentiates the responses of the OECD health systems to economic crises.

\subsection{Models of health systems in OECD countries}

Table 1 shows a division of OECD member states according to the health care model applied. Unlike in the study of van der Zee and Kroneman (2007) who have assigned Western European countries to either the Bismarck or Beveridge models, here, also two other models were distinguished. The market-oriented model groups countries with more than $40 \%$ share of private financing in current health expenditure and four non-European countries constitute this group.

2 The notion of a recession country-year denotes a single case of a country $x$ in period $t$ when GDP growth was negative. 
The fourth group, labelled 'systems in transition' consist of six Central European states. It is argued here that these economies' health systems are not mature enough to be assigned to one of the traditional models. In the literature, they are sometimes referred to as former Semaschko model countries (Birula-Białynicki, 2010, pp. 1-15), however, labelling them as systems 'in transition' is more appropriate nowadays (Antoun et al., 2011, pp. 436-448).

The Polish health system appears to be an example of this transition with the fund collection based on a social security mechanism but with only a single payer, which makes it different from the traditional Bismarck solution based on competing third-party payers. Moreover, as the efficiency analysis evidence suggest the transition OECD economies should not be classified as the Bismarck-type as they differ significantly from the Western European SHI systems in terms of health status, health expenditure as well as efficiency achievements (Eyszczarz, 2014).

\subsection{Dynamics of health systems measures}

Table 2 shows an average annual growth rate (AAGR) of the measures describing OECD health systems' operation. The AAGRs for four health care models are calculated as an unweighted mean of growth rates for the countries included in the respective groups.

The values of every measure used exhibit a growing trend during the period investigated. However, the calculated AAGRs show that the dynamics for the four models differed in health status, health expenditure and physicians' density. The improvement of health status was most rapid in the market-oriented countries with AAGR around $0.5 \%$ for both men and women, while the progress in this respect was twice as little in the transition economies. As far as the Bismarck and Beveridge models are concerned, the former proved to be superior in improving the longevity of a population. When it comes to the health spending dynamics, the model characterized by the highest cost containment inclination was the one 'in transition', whereas the social insurance model was the one with expenditure growing fastest. Doctors' availability grew during the period in all four models with the highest AAGR in the countries with market-oriented health care and the lowest in the transition countries.

\subsection{Model of health care and systems' responses to economic crises}

The data reported in table 3 attempt to differentiate the responses of health systems to economic crises according to the model applied. The values in the table 3 . show the share of years in which the dynamics of the four measures describing health system operation was lower than AAGR for a particular country33.

${ }^{3}$ For example, AAGR for female LE in Austria during the period of 1970-2013 was $0.31 \%$. In three out of the four years when GDP in Austria declined, the dynamics of female LE was lower than average (1975 - 0.00\%; $1978-0.26 \% ; 2009--0.12 \%$ ), while 
The data show that both female and male LE was most vulnerable to the negative effects of economic stagnation in the Bismarck countries. In around two out of the three country-years (64.7\% for women and $66.7 \%$ for men) investigated the dynamics of health status during GDP decline was lower than on average. This shows that in most cases in the SHI countries recession impeded growth in population health improvement. There was a similar LE pattern in the transition economies; however, its magnitude was comparatively high only for women. For men, it were only the Bismarck countries that were characterized by more than half of the recession years with lower-than-average health improvement. The group with the best performance in terms of health status responses to economic downturns was the market-oriented countries with the shares for both genders rounding close to $40 \%$.

The dynamics of health expenditure also differed with the health care model applied. Unlike in other three measures investigated here, the increase in health spending is not considered to be a strictly positive trend. In the context of cost-containment policies applied in recent decades the increase in health expenditure, especially in the times of economic downturns, might be considered as a negative tendency (Abel-Smith \& Mossialos, 1994, pp. 89-132; Carrin \& Hanvoravongchai, 2002). If we accept this reasoning, the systems in transition proved to be the ones with the most favourable trends in health expenditures during economic crises. In as many as $40 \%$ of country-years during economic crises transition economies succeeded in containing the increase of health expenditure by more than on average. On the other hand, it was less than $8 \%$ of country-years when market-oriented systems managed to limit health spending increase by more than on average. Of the two traditional public-based models, the Beveridge countries proved to apply more effective cost-containing policies during economic downturns as compared to the Bismarck countries.

When it comes to doctors' density the trends show that in most of the country-years of crises the dynamics of the measure was lower as compared to AAGR. $80 \%$ of cases in the countries with the market-oriented model were characterized by a lower-than-average increase in doctors' availability. This shows that the countries relying predominantly on private financing failed to sustain the average rate of human resources increase during recessions. In each of the three other health care models the respective share was higher than 50\% of country-years showing that health systems experience deterioration in doctors' availability when economies collapse.

\section{Conclusion}

The purpose of this research was to determine whether health system institutional variation, particularly the model of health care applied, is related to health

in one year the dynamics was higher than average (1981 - 0.53). Thus, the share for Austria is $75 \%$. Analogical reasoning applies for all the countries investigated and table 3 reports shares for all the countries with a particular model. 
systems' responses to economic downturns. To do so, the data for OECD countries (1970-2013) was used and the research was based on identifying the shares of recession years when the dynamics of health system operation measures was lower than on average for a particular country.

The results suggest that health care models are related with systems' responses to economic slumps. The Bismarck-type countries perform poorly in health status improvement in the years of GDP decline. They are also relatively incapable of containing health care costs which might be particularly important during recessions. On the other hand, when the economy slows down, these countries do not fail in securing access to physicians. The Beveridge-type countries perform substantially better in health status improvement during stagnation; they also seem to have better cost-containment policies but they provide less security in terms of human resources availability. The market-oriented countries are in a superior position in terms of health status improvement when economies collapse; however, they fail to restrict health expenditure increase and to sustain the dynamics of doctors' accessibility. Finally, the systems in transitions are characterized by a relatively low performance in female health status improvement during recessions, a moderate situation in securing access to physicians and greatest possibilities of containing costs of health care.

The results of the analysis show that none of the health care models performs better than other models in terms of all four measures examined. For the policymakers, the results imply that there is no universally superior model of health care organization that allows for meeting all the complex objectives that health systems are faced with. In fact, these objectives might be seen as contradictory; securing high availability of resources that can lead to health improvements is intrinsically associated with a lower ability to restrict an excessive health expenditure growth.

\section{References}

Abel-Smith, B., \& Mossialos, E. (1994). Cost containment and health care reform A study of the European Union. Health Policy, 28(2). doi:10.1016/0168-8510(94)90030-2.

Antoun, J., Phillips, F., \& Johnson, T. (2011). Post-Soviet transition: Improving health services delivery and management. Mount Sinai Journal of Medicine, 78(3). doi:10.1002/msj.20261.

Birula-Białynicki, P. (2010). Wielowymiarowe porównania systemów zdrowotnych w krajach OECD w kontekście realizowanych modeli ochrony zdrowia. Prace Naukowe UE we Wroctawiu, 112.

Carrin, G., \& Hanvoravongchai P. (2002). Health care cost-containment policies in high-income countries: How successful are monetary incentives? WHO Discussion Paper, 2.

Docteur, E., \& Oxley, H. (2003). Health-care systems: Lessons from the reform experience. OECD Health Working Papers, 9. doi:10.2139/ssrn.1329305. 
Lee, S.Y., Chun, C.B., Lee, Y.G., \& Seo, N.K. (2008). The National Health Insurance as one type of new typology: The case of South Korea and Taiwan. Health Policy, 85(1). doi:10.1016/j.healthpol.2007.07.006.

Łyszczarz, B. (2014). Ocena efektywności systemów opieki zdrowotnej w krajach OECD. Warszawa: Wolters Kluwer.

Mills, A.J., \& Ranson M.K. (2012). The design of health systems. In M.H. Merson, R.E. Black, \& A.J. Mills (Eds.), Global health: Diseases, programs, systems, and policies, 3rd ed. New York: Jones \& Bartlett.

OECD. (2015). OECD Health Statistics 2015 (database). Retrieved 09.04.2015 from http://www.oecd.org.

Suhrcke, M., \& Stuckler D. (2012). Will the recession be bad for our health? It depends. Social Science \& Medicine, 74(5). doi:10.1016/j.socscimed.2011.12.011. van der Zee, J., \& Kroneman M.W. (2007). Bismarck or Beveridge: A beauty contest between dinosaurs. BMC Health Services Research, 7. doi:10.1186/1472-6963-7-94.

WHO. (2000). World health report 2000. Health systems: Improving performance. Retrieved 09.09.2015 from http://www.who.int.

\section{Acknowledgements}

Author contributions: author have given approval to the final version of the article. 


\section{Appendix}

Table 1.

Classification of OECD countries according to the health care system model implemented

\begin{tabular}{cc}
\hline Health care model & Countries \\
\hline Bismarck (SHI) & Austria, Belgium, France, Germany, Greece (until 1982), Israel, Italy (until 1977), \\
& Japan, Luxembourg, Netherlands, Portugal (until 1978), Spain (until 1985), Switzerland, \\
Turkey & Australia, Canada, Denmark, Finland, Greece (from 1983), Iceland, Ireland, Italy (from \\
Beveridge (NHS) & 1978), New Zealand, Norway, Portugal (from 1979), Spain (from 1986), Sweden, United \\
Kingdom & Chile, Korea, Mexico, United States \\
Market-oriented & Czech Republic, Estonia, Hungary, Poland, Slovakia, Slovenia \\
\hline
\end{tabular}

Information: SHI — social health insurance; NHS — national health services.

Source: Own preparation based on data from OECD (2015) and van der Zee \& Kroneman (2007).

Table 2.

Average annual growth rate of measures describing health systems operation in OECD countries (1970-2013)

\begin{tabular}{|c|c|c|c|c|}
\hline \multirow{2}{*}{ Health care model } & \multicolumn{4}{|c|}{ Average annual growth rate (AAGR) (\%) } \\
\hline & Female_LE & Male_LE & HE_GDP & Doctors \\
\hline Bismarck (SHI) & 0.37 & 0.40 & 2.43 & 2.39 \\
\hline Beveridge (NHS) & 0.25 & 0.31 & 1.55 & 2.14 \\
\hline Market-oriented & 0.45 & 0.51 & 2.03 & $3.11^{*}$ \\
\hline Systems in transition & 0.25 & 0.26 & 1.38 & 1.02 \\
\hline
\end{tabular}

Information: Female_LE — female life expectancy at birth; Male_LE - male life expectancy at birth; HE_GDP — current health expenditure as a share of GDP; Doctors - number of physicians per 1000 population. * - Chile was excluded from the calculation of doctors' availability dynamics due to a low number of observations. The average annual growth rate for each of the four health care models was calculated as a mean of values for countries that constitute a particular group.

Source: Own calculations based on data from OECD (2015).

Table 3.

Share of recession country-years with lower dynamics than AAGR

\begin{tabular}{crrrr}
\hline \multirow{2}{*}{ Health care model } & \multicolumn{3}{c}{ Share of years with dynamics lower than average for a country (\%) } \\
& Female_LE & Male_LE & HE_GDP & Doctors \\
\hline Bismarck (SHI) & 64.7 & 66.7 & 22.7 & 51.3 \\
Beveridge (NHS) & 48.7 & 48.7 & 28.2 & 70.9 \\
Market-oriented & 43.8 & 37.5 & 7.7 & 80.0 \\
Systems in transition & 65.2 & 47.8 & 40.0 & 61.9 \\
\hline
\end{tabular}

Information: as in table 2 .

Source: Own calculations based on data from OECD (2015). 
